Radio-Technology

By B. F. Weller. Pp. viii + 358. (London : Chapman and Hall, Ltd., 1943.) 2ls. net.

$7 \mathrm{HE}$ author of this book is a practical radioengineer, who has had some experience in teaching the subject; and he has endeavoured to provide an intermediate practical text-book suitable for students preparing for some of the recognized examinations in radio-communication. The reader is assumed to have a fundamental knowledge of electricity and magnetism, including the principles of alternating currents, and a mathematical ability normally associated with practical electrical engineering.

The scope of the work is approximately that of the terminal equipment-transmitters and receiversrequired for radio-communication purposes. After an introductory chapter on alternating currents and resonant circuits, the general principles of the production of radio-frequency oscillations are described in Chapter 2. The properties of thermionic valves, from diodes to pentodes, are next dealt with, together with the circuit arrangements used for applying valves as rectifiers, amplifiers and oscillators.

This leads to a treatment of the principles of radio transmitters, and the $\mathrm{k}$ ying and modulation methods used for telegraphy and telephony. Two chapters are then devoted to the general principles of reception, and the supersonic heterodyne type of receiver now so widely used for radio-communication purposes. A chapter on the various types of modern aerial systems and their relevant characteristics concludes the kook.

The treatment throughout is descriptive of the technological principles of the subjeet without reference to any specific equipment, and should thus prove valuable to the practical operating and installation engineer who desires to acquire a closer fundamental knowledge of the branch of engineering in which he is eng ged.

\section{The Manure Note Book}

A Handy Guide for Manure Manufacturers and Merchants, Farmers, Agricultural Students and Horticulturalists. By John Stewart Remington. Pp. $v+58$. (London : Leonard Hill, Ltd., 1943.) 3s. $6 d$.

\section{$\mathrm{T}$} HE first chapter of this book is devoted to a brief account of the constitution of soils and the composition of plants. Then follow two short chapters on the origin and use of farmyard manure and fertilizers supplying nitrogen. Chapter 4 is headed "Phosphatic Manures", but after a description of the commoner phosphatic fertilizers, gives an account of the origin, characteristics and uses of potash manures and lime, the residual effects of manures and the manurial requirements of some of the common crops. A short chapter on manures for fruit trees is followed by a collection of manure recipes for a wide range of agricultural and horticultural crops and a number of conversion tables, and tables of equivalence relating to materials used in the manufacture of fertilizers. The last fifteen pages of the book are devoted to tables showing the percentage of any nutrient in a fertilizer mixture from the weight of the fertilizer salt supplying that nutrient which is included in each ton of the mixture.

The manure recipes and the manurial requirements of crops are dealt with from the pre-war point of view. No reference is made to the present restrictions on the use of fertilizers or to some of the more modern fertilizers. Some of the fertilizer recommendations are not in agreement with the results of recent experimental work; and the inclusion of sulphate of potash in a special turnip and mangold manure while kainite is used in a potato manure seems dincult to justify. The book is likely to ke appreciated more by the manure manufacturer than the farmer. F. $H$.

\section{The Natural Develonment of the Child}

A Guide for Parents, Teachers, Students and Others. By Dr. Agatha H. Bowley. Second edition. Pp. xvi $+184+30$ plates. (Edinburgh : E. and S. Livingstone, 1943.) $8 s .6 d$. net.

$T$

HE appearance of a second edition of this work, little more than a year after, it was originally issued, is itself sufficient tribute to the way it has been received. Dr. Bowley set out to help parents and teachers who need guidance about the emotional development of children. To do this she has not only read widely - each chapter ends with a list of references-but also has arranged various investigations at the school psychological departments with which she has been connected. Having collected the material, the author has not impaired the value of her work by the inclusion of technical descriptions; the book is intended for the non-specialist and in no part does it become too difficult for them. It is crammed with useful information for parents and teachers and, albeit inadvertently, shouts the need for more and more parents and teachers who are really fitted to guide young children towards maturity. "The Natural Development of the Child" continually raises the question as to whether the ability to produce a child is in itself sufficient justification for the parent to constitute himself or herself the most suitable guardian of the child. One also wonders if the ability to teach reading or writing or any of the 'ologies' should continue to be recognized as the main qualification required to help the child in its adjustment to life.

T. H. H.

\section{Map Reading and Avigation}

An Introduction. By Richard M. Field and Harlan T. Stetson. Pp. xiiit 129. (London: Chapman and Hall, Ltd., 1943.) 15s. net.

$7 \mathrm{HE}$ aim of this book is to provide an introduction 1 to the subject for air cadets. The first half treats of map-reading from the point of view of the aviator, and is illustrated entirely from American maps, and even these, on account of censorship, have had to be chosen with discretion. The treatment is summary and omits some of the more familiar considerations generally embraced in the study of maps for surface travel. Particular attention is paid to the relation between aerial photographs, block diagrams and topographical surveys, and many well-devised exercises and problems are included. If space was a consideration, it is difficult to understand why a brief résumé of the physiographic region of the United States and Canada and a section on the moon should be included.

The second half of the book, and probably the most useful, is an introduction to air navigation for which the author uses a word of doubtful legitimacy, 'avigation'. This section is clear and lucid, and requires a minimum of mathematical skill. The relative merits of Mercator and the Lambert conformal projections are discussed. The diagrams are well drawn. A list of reference books and charts includes only United States publications. On the whole, it is a useful book and is admirably illustrated. 